\title{
Ácido fólico y defectos del tubo neural en Atención Primaria
}

A. I. GonzÁlez GonZÁlez, M. Ma García CARBallo ${ }^{1}$ Especialista en Medicina Familiar y Comunitaria. Responsable de Servicios Sanitarios. Gerencia de Atención Primaria del Área 10 de Madrid.

'Especialista en Medicina Familiar y Comunitaria. Centro de Salud El Greco. Getafe. Área 10. Getafe, Madrid

\section{RESUMEN}

Los defectos del tubo neural (DTN) son malformaciones graves y relativamente comunes que se originan al comienzo de la gestación. La suplementación con folatos se ha demostrado como una medida eficaz en la prevención primaria de dichos DTN. La evidencia sobre la prevención del primer episodio y la recurrencia de estas malformaciones es tal, que las recomendaciones sobre la oferta de ácido fólico rutinaria a mujeres en edad fértil son apoyadas por las autoridades sanitarias. Los médicos de Atención Primaria, como responsables del primer escalón de atención a la población de mujeres, deben conocer cuáles son esas recomendaciones y cómo se pueden llevar a cabo.

Palabras clave: Ácido fólico. Defectos del tubo neural. Embarazo. Prevención. Atención Primaria.
Folic acid and neural tube defects in Primary Health Care

\section{ABSTRACT}

Neural tube defects are serious congenital abnormalities and relatively common that appear $d u$ ring the first months of pregnancy. The intake of folic acid supplements has demonstrated to primary prevent such defects. The evidence about the prevention of the first episode and the recurrence of neural tube defects is so strong that health authorities recommend a routinely offer of folic acid to women. Primary Health Care Physicians are responsible for such recommendations and must know how they must be done.

Key words: Folic acid. Neural tube defects. Pregnancy. Prevention. Primary Health Care.

\section{LOS DEFECTOS DEL TUBO NEURAL}

Durante el desarrollo embrionario se produce el cierre del tubo neural en torno a las 6 semanas tras la concepción. Los llamados defectos del tubo neural (DTN) se producen como consecuencia de alteraciones en el cierre del mismo, y pueden tener lugar a dos niveles: cerebro y columna vertebral ${ }^{1}$. Este defecto a nivel del cerebro da lugar a la anencefalia y al encefalocele, y a nivel de la columna vertebral constituye la espina bifida. La anencefalia se caracteriza por la ausencia total o parcial del cerebro incluida la bóveda craneal y la piel que la recubre, y el encefalocele supone la herniación del cerebro y/o las 
meninges a través de un defecto en el cráneo. Tanto la anencefalia como el encefalocele son incompatibles con la vida. La espina bífida agrupa una serie de malformaciones cuya característica común es una hendidura a nivel de la columna vertebral que puede ir acompañada de un prolapso de las meninges, lo que se denomina meningocele o incluso de la médula espinal originando el mielomeningocele. Éste se considera la forma más incapacitante de espina bífida, y se caracteriza por la exposición de tejido nervioso recubierto por meninges a través de un defecto de la columna vertebral; ello origina una lesión permanente de la médula espinal y los nervios espinales produciendo diversos grados de parálisis así como pérdida del control de los esfínteres vesical e intestinal.

Alrededor de la mitad de los casos de DTN corresponden a una espina bífida aislada, y aproximadamente la otra mitad a una anencefalia con o sin espina bífida. Las consecuencias clínicas son muy serias, los fetos anencéfalos mueren antes o poco después del parto, y una parte de los nacidos con espina bífida llegan a la edad adulta pero con parálisis de miembros inferiores y un grado variable de incontinencia urinaria y fecal ${ }^{2}$.

Las causas de los DTN aislados no se conocen con exactitud, pero se piensa que la mayoría de estos defectos presentan un origen multifactorial, de forma que podrían influir factores genéticos y ambientales. El componente genético es complejo y no bien conocido. En cuanto a los factores ambientales, según múltiples investigaciones epidemiológicas, constituyen una de las causas más importantes de los DTN, siendo el déficit de folatos la circunstancia más firmemente relacionada ${ }^{3}$.

La incidencia mundial de los DTN oscila entre 1-8 casos por cada 10.000 nacidos vivos, con un aumento de dicha incidencia en individuos caucasianos y en los niveles socioeconómicos bajos, existiendo variaciones geográficas (la incidencia más alta se encuentra en Gales y la más baja en la costa oeste de EE.UU.) ${ }^{4}$.

En España la prevalencia de los DTN es de 8 por 10.000 nacidos vivos ${ }^{5}$. El riesgo de presentar un DTN aumenta cuando existen antecedentes familiares, de forma que mujeres con un embarazo previo afectado presentan un riesgo de recurrencia del 2-3\% (10 veces más que la población general) y con dos embarazos previos de un 10-15\%. Este riesgo también está aumentado en las mujeres con diabetes tipo 1 y en las que reciben tratamiento con algunos anticomiciales (fenitoína, valproico y carbamacepina).

\section{FOLATOS}

El ácido fólico o ácido pteroilglutámico es una vitamina hidrosoluble del grupo B sintetizada por las bacterias de la flora intestinal y presente en pequeña cantidad en algunos alimentos. Los folatos tienen dos efectos biológicos conocidos: a) actúan como cofactores de enzimas que son esenciales para la síntesis del ADN y ARN; y b) son necesarios para la transferencia de grupos metilo en el ciclo de metilación de los aminoácidos, un paso fundamental en la reconversión de homocisteína en metionina'.

Los folatos están presentes en una gran variedad de alimentos, sobre todo en los vegetales de hoja verde (espinacas, guisantes, coles de Bruselas, judías), frutas (naranja, aguacate), hígado, frutos secos (nueces, almendras), cereales y legumbres (Tabla I). A pesar de que las necesidades de folatos se pueden cubrir a partir de todos estos alimentos, hay que tener en cuenta que para ello la estructura básica del ácido pteroilglutámico debe permanecer estable. Factores como el calor (cocción), la oxidación y la luz ultravioleta (conservación) son capaces de romper esta molécula e inactivarla. Por ello, es muy probable que una dieta compuesta exclusivamente por alimentos cocidos sea pobre en folatos. Las frutas y verduras frescas que no necesitan ser cocinadas para consumirse son las responsables del mayor aporte de folatos en la dieta diaria del ser humano.

Los folatos de los alimentos, que en su mayoría se presentan en forma de poliglutamatos, se absorben a nivel del tercio proximal del intestino delgado donde se transforman en monoglutamatos, están presentes en prácticamente todos los tejidos corporales, y se almacenan la mayor parte en el hígado.

\begin{tabular}{|lc|}
\multicolumn{2}{c}{ Tabla I } \\
\cline { 1 - 2 } CONTENIDO DE FOLATOS DE ALGUNOS ALIMENTOS \\
\hline Alimento & $\mu \mathbf{g} / \mathbf{1 0 0} \mathbf{g}$ \\
\hline Soja & 240 \\
Higado & 227 \\
Legumbres & 180 \\
Acelgas, espinacas & 140 \\
Almendras, avellanas & 110 \\
Remolacha, puerro & 90 \\
Guisantes y habas & 78 \\
Nueces & 77 \\
Naranja, mango & 37 \\
Lechuga, escarola, espárrago & 34 \\
Tomate, maíz & 26 \\
Huevo de gallina & 24 \\
Harina de trigo, pan & 22 \\
Plátano, mandarina & 21 \\
Queso manchego & 20 \\
Sardinas, arenques & 16 \\
Alcachofas, calabacín & 13 \\
\hline
\end{tabular}




\section{DÉFICIT DE FOLATOS}

La deficiencia de folatos puede ser debida a diferentes causas: a) ingesta inadecuada; b) absorción deficiente; c) aumento del consumo; y d) alteraciones en su utilización. Además de una dieta insuficiente hay otras situaciones en las que puede existir un déficit de folatos, como el alcoholismo o determinadas enfermedades intestinales. Otra situación de déficit puede aparecer como consecuencia de interacciones medicamentosas, al inhibirse la enzima metilen-tetrahidrofolato-reductasa (Tabla II).

\section{Tabla II}

\section{SITUACIONES DE DÉFICIT DE FOLATOS}

\section{Dieta insuficiente}

2. Aumento del consumo: embarazo, lactancia, anemia

hemolítica, dermatitis exfoliativa

3. Enfermedades intestinales: esprue tropical, enfermedad celíaca, síndrome de intestino corto

4. Interacciones farmacológicas: (inhibidores de la metilen-tetrahidrofolato reductasa)

Anticonceptivos orales (ACHO)

Alcohol

Cimetidina

Cotrimoxazol

Fluoracilo

Isoniacida

Litio

Metotrexate

Pentamidina

Pirimetamina

Triantereno

Durante el embarazo las necesidades maternas de folatos aumentan, dada la importancia de la síntesis de ácidos nucleicos y proteínas durante la embriogénesis, así como la gran velocidad de crecimiento y desarrollo fetal durante los primeros meses de la gestación.

Según las Recommended Dietary Allowances (RDA), o raciones dietéticas recomendadas, de la National Academy of Sciences, Food and Nutrition Board, las cantidades diarias de folatos que una mujer adulta necesita son de 200 microgramos/día, mientras que en una mujer gestante las necesidades ascienden a $400 \mathrm{microgramos} / \mathrm{dí}^{7}$.

Un régimen dietético bien equilibrado contiene de 1 a 1,5 mg de ácido fólico, pero la mayor parte se inactiva con la cocción de muchos de los alimentos ${ }^{8}$, y no se ha demostrado que sea efectivo a la hora de elevar los niveles de ácido fólico en sangre comparado con la fortificación de los alimentos o el suplemento en comprimidos ${ }^{9}$. Los folatos de la comida se encuentran en forma de poliglutamatos, que deben ser convertidos a monoglutamatos en las primeras porciones del intestino delgado. Los suplementos de ácido fólico sintético se encuentran en forma de monoglutamatos y ofrecen por lo tanto una mejor biodisponibilidad que los folatos de fuentes naturales.

\section{DÉFICIT DE FOLATOS Y DTN}

Aunque la mayoría de los DTN presentan un origen multifactorial, se ha podido demostrar que la deficiencia del ácido fólico durante la etapa periconcepcional se correlaciona con la prevalencia de estos defectos ${ }^{10}$.

La evidencia más convincente que demuestra una reducción de la recurrencia de estos defectos con el suplemento de ácido fólico es la del ensayo clínico multicéntrico aleatorizado del United Kingdom Medical Research Council ${ }^{11}$. Después de estudiar a 1.195 embarazos, se encontró que el suplemento con $4 \mathrm{mg}$ al día de ácido fólico por sí solo reduce la recurrencia de los defectos del tubo neural en un $72 \%$ (odds ratio (OR): 0,32 ; intervalo de confianza (IC) $95 \%$ : 0,16-0,64).

El estudio de "Czeizel”, un ensayo clínico húngaro en 4.753 mujeres, ofrece la mejor evidencia de que los suplementos de ácido fólico periconcepcional previenen de forma primaria los defectos del tubo neural ${ }^{12}$ (OR: 0,13; IC 95\%: 0,03-0,65). Aquellas mujeres que planeaban quedarse embarazadas fueron asignadas de manera aleatorizada a recibir $0,8 \mathrm{mg}$ de ácido fólico y un placebo al día al menos un mes antes de la concepción, y al menos hasta el segundo mes de embarazo. Las malformaciones congénitas aparecieron con mayor frecuencia en el grupo que recibió el placebo de forma significativa (22,9 por 1.000 vs 13,3 por $1.000, \mathrm{p}=0,02)$.

Debido a que otros estudios realizados con controles no aleatorizados consiguieron niveles comparables de prevención secundaria con una dosis diaria de $0,36 \mathrm{mg}$, la mayoría de las políticas sanitarias han optado por una dosis de $0,4 \mathrm{mg}$ al día como la recomendada para las mujeres que piensan quedarse embarazadas y no presentan antecedentes de $\mathrm{DTN}^{13}$. Parece poco probable que pueda realizarse algún ensayo clínico de prevención primaria para clarificar la dosis mínima requerida.

No existe todavía certeza sobre si un aumento en el consumo de alimentos ricos en folatos puede ofrecer la dosis recomendada de $0,4 \mathrm{mg}$ al día, y si es realizable por la mayoría de las mujeres tanto en países desarrollados como subdesarrollados.

Actualmente una de las principales preocupaciones radica en que dosis mayores de $1 \mathrm{mg}$ de ácido fólico pueden enmascarar deficiencias de vitamina B12 en ciertos individuos reduciendo la anemia macrocítica asociada, e incluso pudiendo producir lesiones neurológicas irreversibles ${ }^{14}$. 
En la actualidad se están realizando ensayos clínicos con el fin de determinar el papel que desempeñan los folatos en la prevención de la enfermedad cardiovascular. Estos hallazgos podrían contribuir a tomar más y mejores decisiones sobre los riesgos y beneficios de la fortificación de productos básicos.

La conclusión más importante es que la mayoría de los casos de DTN pueden ser prevenidos consumiendo cantidades adecuadas de folatos antes de la concepción y en las etapas iniciales del embarazo.

\section{PROFILAXIS DE LOS DTN CON FOLATOS DURANTE EL EMBARAZO: RECOMENDACIONES GENERALES}

La suplementación periconcepcional con folatos tiene como objetivo disminuir el riesgo de recurrencia y de la primera ocurrencia de los DTN. El efecto protector demostrado de la suplementación con folatos durante el periodo periconcepcional sobre los DTN, hace que quede claramente indicada la necesidad de aumentar el ingreso de folatos tanto en las mujeres con alto riesgo de DTN como en la población general.

A partir del estudio del British Medical Research Council Vitamin Study (MRC) en 1991 ${ }^{11}$, los American Centers for Disease Control (CDC) publicaron las recomendaciones sobre la suplementación con folatos en mujeres con alto riesgo de recurrencia de $\mathrm{DTN}^{15} \mathrm{y}$, posteriormente en la población general ${ }^{16}$. Estas recomendaciones se resumen en:

1. Toda mujer con el antecedente de un embarazo con un feto o recién nacido con un DTN debe recibir información sobre el aumento de riesgo en un embarazo posterior, y que dicho riesgo se puede reducir con la toma de suplementos de folatos.

2. Toda mujer con el antecedente de un embarazo con un feto o recién nacido con un DTN debe ser advertida de la necesidad de consultar con su médico tan pronto como planifique un nuevo embarazo. Si no existen contraindicaciones, deberá tomar suplementos de folatos tan pronto decida quedarse embarazada (al menos 4 semanas antes) y durante el primer trimestre de embarazo.

3. Los suplementos de folatos deben tomarse bajo prescripción médica, en forma de monofármacos, ya que los multivitamínicos de prescripción libre, para alcanzar las dosis adecuadas de ácido fólico, pueden aportar dosis peligrosas de vitaminas A y D.

4. Todas las mujeres en edad fértil deben tener en cuenta a la hora de planificar su embarazo la necesidad de consumir cantidades suficientes de folatos, bien a través de la dieta o bien con suplementos farmacológicos.

Actualmente existe consenso en las recomenda- ciones emitidas por la mayoría de las sociedades científicas y organismos internacionales para la prevención primaria de los $\mathrm{DTN}^{16-18}$ :

1. En situaciones de bajo riesgo (mujeres sin antecedentes de DTN): dosis inferiores a $1 \mathrm{mg} /$ día. Fuerza de recomendación $A$ para $0,8 \mathrm{mg} /$ día y $B$ para $0,4 \mathrm{mg} /$ día desde 4 semanas antes de la concepción y hasta 12 semanas después de la concepción con niveles de evidencia $I$ y $I I-2$.

2. En situaciones de alto riesgo:

- Mujeres con un embarazo previo afectado de DTN: suplementos de $4 \mathrm{mg} /$ día desde 4 semanas antes de la concepción hasta 12 semanas después de la concepción. Fuerza de recomendación $A$, nivel de evidencia $I$.

-Otros factores de riesgo: mujeres con antecedentes familiares de DTN (distintos de un hijo) de ella o de su pareja, vegetarianas, enfermas de sida, diabéticas y epilépticas. Al carecer de estudios realizados en estas situaciones, no hay recomendaciones al respecto, por lo que, en cada caso deberá valorarse riesgos y beneficios de la administración de $4 \mathrm{mg}$ /día.

\section{PAPEL DEL MÉDICO DE ATENCIÓN PRIMARIA}

Como profesionales sanitarios, una posible estrategia a seguir, sería intentar identificar a todas las mujeres de alto riesgo (antecedentes de DTN, historia familiar de DTN, consumidoras de anticonvulsivantes, mujeres que siguen dietas inadecuadas) y centrar los esfuerzos en este grupo. Una alternativa podría ser dirigirse a la población general de mujeres en edad fértil para que consuman suplementos de folatos desde el momento en que planifiquen un embarazo.

Básicamente son tres las opciones para conseguir unos niveles de folatos aceptables entre esta población:

1. Consejo y educación sobre la alimentación: En condiciones ideales, se podría aumentar el consumo de folatos mejorando la alimentación de la población al recomendar alimentos ricos en folatos como los vegetales frescos y las frutas. Sin embargo, la modificación de los hábitos alimenticios de una población es una tarea harto difícil. En primer lugar porque una gran parte de las mujeres en edad fértil desconocen los efectos beneficiosos de una dieta rica en folatos para la prevención de los $\mathrm{DTN}^{19}$; por otra parte es poco probable que todas estas mujeres cuenten con los recursos económicos, el tiempo, la educación y el interés necesarios para asegurar el cumplimiento de estas recomendaciones sobre el consumo de folatos. Se ha podido demostrar que aunque se aumente el aporte de folatos a través de la dieta al aconsejar cambios en el tipo de alimentación, este aumento no es sufi- 
ciente para modificar de manera significativa el nivel de folatos eritrocitarios ${ }^{20}$.

2. Fortificación de los alimentos con folatos: $\mathrm{Se}$ han establecido dos estrategias adicionales para aumentar el consumo de folatos en todas las mujeres en edad fértil: una consiste en la producción y venta de productos enriquecidos con folatos, y otra en la adición de ácido fólico a componentes alimentarios básicos como la harina. La primera de estas estrategias se acepta en muchos países pero dado su alto precio no es una estrategia que asegure una prevención para todas las mujeres. Existe discusión sobre la segunda estrategia, los beneficios y riesgos de añadir folatos para todos los grupos de edad y sexo, ya que ello implica establecer un nivel de consumo de ácido fólico que prevenga la aparición de DTN pero que no perjudique la salud de otros grupos. El principal argumento para no administrar suplementos de folatos con el alimento es que expone a toda la población a una intervención que sólo se dirige a las mujeres embarazadas. Por otra parte, sólo con la fortificación de estos alimentos (harina y cereales), tampoco se ha demostrado que se alcancen los niveles de folatos recomendados. La revisión realizada al respecto por la Cochrane Library considera necesario llevar a cabo nuevos estudios para valorar la fortificación con folatos de los alimentos básicos de forma universal ${ }^{21}$.

3. Suplementos farmacológicos de folatos: En la actualidad ésta es la medida más segura y eficaz para conseguir un aporte adecuado de folatos tanto en mujeres de alto como bajo riesgo. Esta suplementación debe llevarse a cabo según las recomendaciones anteriormente señaladas en cuanto a dosis, iniciándose 4 semanas antes de la concepción, y hasta el primer trimestre de embarazo. La suplementación ha de ser diaria y con un monofármaco; no se recomienda la utilización de preparados polivitamínicos ya que para alcanzar las dosis necesarias de folatos podrían administrarse cantidades peligrosas de otras vitaminas y nutrientes ${ }^{21}$. El principio activo a emplear es el ácido fólico, y solamente está justificado la utilización de ácido folínico o folinato cálcico en caso de existir un déficit de folatos como consecuencia de una interacción medicamentosa que haya inhibido la enzima metilen-tetrahidrofolato-reductasa; en el resto de las situaciones de déficit el ácido folínico no presenta ventajas respecto al ácido fólico y es entre 4-10 ve- ces más caro. Los folatos sintéticos o farmacológicos presentan una biodisponibilidad mayor que los folatos aportados mediante la dieta al encontrarse en forma de monoglutamatos. El principal inconveniente para la suplementación farmacológica con folatos es que muchas mujeres no planifican sus embarazos, y por tanto no acuden a la consulta preconcepcional a informarse ${ }^{22,23}$. En consecuencia, es fundamental llevar acabo una intensa campaña educativa y publicitaria desde los centros de planificación familiar, servicios de salud laboral y, por supuesto, desde la consulta de Atención Primaria.

Sería deseable que la totalidad de médicos de atención primaria conocieran las recomendaciones generales de la suplementación con folatos para la prevención de los DTN para actuar en consecuencia. Todas las mujeres con antecedentes de un feto diagnosticado de un DTN deben recibir información sobre el riesgo de recurrencia en un embarazo posterior ${ }^{24}$. La población general de mujeres en edad fértil debería recibir información sobre el efecto protector del ácido fólico, y sobre la necesidad, si no hay contraindicaciones, de tomar suplementos diarios de folatos antes de quedarse embarazadas y hasta el primer trimestre de embarazo.

El seguimiento que desempeñan cada vez más médicos de Atención Primaria de la toma de anticonceptivos puede ser un buen momento para recordar estas premisas.

El médico de Atención Primaria al encontrarse en el primer escalón de atención a la población representa un papel muy importante como educador sanitario a la hora de garantizar una adecuada profilaxis de los DTN.

\section{CORRESPONDENCIA:}

\section{Ana I. González González}

Gerencia de Atención Primaria del Área 10 de Madrid Avda. Juan de la Cierva, s/n.

28902 Getafe. Madrid

Tel. 916955198 - Fax: 916955160

e-mail: anaglezglez@hotmail.com

\section{Bibliografía}

1. Van Allen MI, Kalousek DK, Chernoff GF, Juriloff D, Harris M, McGillivray BC. Evidence for multi-site closure of the neural tube in humans. Am J Med Genet 1993; 47: $723-43$.
2. International Clearinghouse for Birth Defects Monitoring Systems. Congenital malformations worldwide: A report from the International Clearinghouse for Birth Defects Monitoring Systems. Amsterdam: Elsevier, 1991. p. 41-51. 
3. Butterworth CE Jr, Bendich A. Folic acid and the prevention of birth defects. Annu Rev Nutr 1996; 16: 73-97.

4. Abramsky L, Botting B, Chapple J, Stone D. Has advice on periconcepcional folate supplementation reduced neural tube defect? Lancet 1999; 354: 998-9.

5. Recomendaciones sobre suplementación con ácido fólico para la prevención de los defectos del tubo neural. Inf Ter Sist Nac Salud 2001; 25: 1-2.

6. Locksmith GJ, Duff P. Preventing neural tube defects: The importance of periconceptional folic acid supplements. Obstetrics \& Gynecology 1998; 91: 1027-33.

7. NRC (National Research Council). Recommended dietary allowances/ Subcommittee on the Tenth Edition of the RDAs, Food and Nutrition Board, Commission on Life Sciences, National Research Council. Washinton, DC: National Academy Press; 1989.

8. Quintas ME, Requejo AM, editores. Nutrición en la mujer en edad fértil. En: Manual de nutrición clínica en atención primaria. Madrid: Editorial Complutense 2000; 6: 56-8.

9. Cuskelly GJ, McNulty H, Scott JM. Effect of increasing dietary folate on red-cell folate: Implications for prevention of neural tube defects. Lancet 1996; 347: 657-9.

10. Elwood M, Little J, Elwood JH, editores. Epidemiology and control of neural tube defects. Oxford: Oxford University Press, 1992.

11. MRC Vitamin Study Research Group. Prevention of neural tube defects: Results of the Medical Research Council Vitamin Study. Lancet 1991; 338: 131-7.

12. Czeizel AE, Dudas I. Prevention of the first occurrence of neural tube defects by periconceptional vitamin supplementation. N Engl J Med 1992; 327: 1832-5.

13. Kirke PN, Daly LE, Elwood JH, for the Irish Vitamin Study Group. A randomised trial of low dose folic acid to prevent neural tube defects. Arch Dis Child 1992; 67: 1442-6.

14. Mills JL. Fortification of foods with folic acid. How much is enough? N Engl J Med 2000; 342: 1442-5.

15. CDC. Use of folic acid for prevention of spine bifida and other neural tube defects-1983-1991. MMWR 1991: 40; 513-6.

16. CDC. Recommendations for the use of folic acid to reduce the number of cases of spine bifida and other neural tube defects. MMWR 1992; 41: 1-7.

17. Canadian Task Force on the Periodic Health Examination Canada. Guide to clinical preventive health care. Otawa: Canada Communication Group, 1994. p. 74-81.

18. Bailón E, Coutado A, del Cura I, Fuentes M. Atención preconcepcional. Actividades preventivas en la mujer. Aten Primaria 2001; 28 (Supl. 2): 189-94.

19. CDC. Knowledge and use of folic acid by women of childbearing age. United State, 1995 and 1998. MMWR 1999; 48: 325-7.

20. Cuskelly GJ, McNukty H, Scott JM. Effect of increasing dietary folate on red-cell folate: implications for prevention of neural tube defects. Lancet 1996; 347: 657-9.

21. Lumley J, Watson L, Watson M, Bower C. Periconceptional supplemmentation with folate and/or multivitamins for preventing neural tube defects (Cochrane Review). En: The Cochrane Library, 2000. Oxford: Update Software.

22. Mathews F, Yudkin P, Neil A. Folates in the periconceptional period: are women getting enough? Br J Obstet Gynaecol 1998; 105: 954-9.

23. Sharpe G, Young G. Most pregnant women do not take folic acid during pregnancy. BMJ 1995; 311: 256.

24. Frame PS, Berg AO, Woolf S. U.S. Preventive Services Task Force: Highlights of the 1996 Report. Am Fam Physician 1997; 55: 567-76. 